\title{
Students' Technology Acceptance, Motivation and Self-Efficacy towards the eSchoolbag: An Exploratory Study
}

\author{
Juan Zheng ${ }^{1}$, Shan $\mathrm{Li}^{1}$, Yunfeng Zheng ${ }^{2}$ \\ ${ }^{1}$ McGill University, Canada \\ ${ }^{2}$ Wuhan Institute of Technology, China
}

\begin{abstract}
The eSchoolbag, as an integrated intelligent teaching and learning platform, has gained great popularity during the last decade, especially in Asia countries. However, few research regarding the eSchoolbag-based learning provides a whole picture of students' ideas towards the eSchoolbag. This study examined students' technology acceptance, motivation and self-efficacy towards the eSchoolbag, especially, how students' learning performances affected their perceptions of the eSchoolbag, which could facilitate the successful implementation of the eSchoolbag in classroom environments. A total of 299 participants were involved in this study, and were divided into two groups based on their annual academic performances using K-means clustering algorithm. The two groups were labelled as the high and low group respectively. In term of technology acceptance, this research found that there was no significant difference on students' perceived ease-ofuse of the eSchoolbag, however, there was a significant difference on students' perceived usefulness. With respect to students' motivation, the result showed no significant differences between the high and low performance groups. But a significant difference was existed on students' self-efficacy between the high and low group, with students in the high group demonstrating higher self-efficacy than students in the low group.
\end{abstract}

\section{Introduction}

The integration of tablet computers (TC) into education has gained popularity all over the world [1]. The palm-size and cost-effective device provides students a technology enhanced learning environment, which has the potential in holding students' attentions in classrooms, and immersing them into authentic problem-solving contexts. When using tablet computers to assist teaching and learning, students' learning trajectories and behaviors can be captured and analyzed by the environment, making the acquisition of personalized and adaptive learning resources available for students. However, it doesn't necessarily mean that distributing the tablet computers into classroombased environment could definitely promote students' learning performances. On one hand, the research regarding how to use the tablet effectively to facilitate students' learning is still unclear, considering that a lack of comprehensive understanding of how students' cognitive, affective, emotional and behavioral factors interplay with the tablet-based learning environment. On the other hand, most of educational applications or systems nowadays failed to integrate teaching and learning processes into one unit [1]. For example, eTextbooks provide students with abundant learning resources on one tablet, reducing the need to carry heavy physical schoolbags. However, neither students can get appropriate instructional support when reading e-Textbooks, nor teachers have knowledge about the students' learning progresses. Teachers cannot effectively manage and monitor students' learning, that's to say, teachers have difficulties in providing targeted scaffoldings according to students' needs [2]. Under this circumstance, an integrated solution known as the eSchoolbag came to researchers' sights.

The eSchoolbag (electronic schoolbag) is not only a technology-rich teaching platform for teachers, but also an intelligent learning environment for students [3]. In classroom context, every student holds a eSchoolbag device which allows them to participate in various activities. Teachers are using the eSchoolbag with administrative functions, so they are able to control students' learning processes by monitoring students' screens, allocating learning resources, organizing group discussions and assigning tasks. In this way, the eSchoolbag meets both teachers' requirements and students' learning needs. Numerous studies have revealed the fact that students' learning performance could be improved by using the eSchoolbag [4][5]. However, there is insufficient research on how students' learning performance affects their perceptions of the eSchoolbag. As such, this study aims to contribute to the body of eSchoolbag research. Specifically, how students' academic performance affects their technology acceptance, learning motivation and selfefficacy towards the eSchoolbag. 


\section{Theoretical Background}

Students are affected by the tags attached with their academic performances. Academic performance is the common assessment that most of schools are using to distinguish students. These kind of academic performance (success or failure, high or low) will significantly affect the students' self-conception more than vice versa [6]. As explained by the role of evaluation and the theory of social comparison, students can develop a sense of self-efficacy and perceived abilities by comparing themselves within the group and with other groups [7]. In other words, students who are deemed as high performers by comparing with others will have higher self-efficacy, while students who consider them as low performers in certain groups are more inclined to have less confidence on their competency and abilities to complete difficulty tasks. In the context of eSchoolbag-based learning, students' academic performance may affect their self-efficacy, as well as their motivation and technology acceptance towards the eSchoolbag. Therefore, it is necessary to examine the influence of academic performance on selfefficacy, motivation and technology acceptance of eSchoolbag for the purpose of promoting effective implementation of the eSchoolbag in classrooms.

\subsection{The eSchoolbag}

According to [3], eSchoolbag is an integrated teaching and learning platform that incorporated with a variety of resources and tools to provoke students' effective cognitive engagement, as well as optimize teachers' effective management of classroom activities and students' learning processes. The design of the eSchoolbag is to optimize teaching and learning by leveraging the affordances of technologies. Specifically, the ultimately goal of the eSchoolbag is to provide students adaptive and personalized learning services (e.g. context-sensitive learning resources, in-time scaffoldings and comprehensive learning management) based on a long-term learning analyses and user modeling. A mature eSchoolbag system is capable of: 1) identifying and tracing student's operations and activities; 2) inferring each individual's decisionmaking processes and relevant correlations with expected learning outcomes on the strength of domain-specific models; 3) deducing learner's unique requirements, characteristics and preferences; and 4) acting correspondingly upon available resources and scaffoldings [8]. The eSchoolbag also aims to provide teachers instructional and technological suggestions on basis of stealth assessments of students' cognitive and behavioral processes. On one hand, the eSchoolbag emphasize the autonomous role of learner in uniquely constructing meanings in an authentic problem- solving context, immersing learners into situated, activity-intensive, and technology-rich learning environment. The individual takes the responsibility to manage, monitor and evaluate their learningrelated behaviors. On the other hand, the eSchoolbag highlights the role of teachers in supporting students' learning.

Typically, an eSchoolbag is composed of electronic textbooks, additional learning resources, subject-related cognitive and metacognitive tools (e.g. search engines, web-based calculator, classified thesaurus, graphic organizer, reasoning flow, concept maps), and administrative functions. The built-in algorithms (by and large, the learning analysis and data mining algorithms) drive the eSchoolbag to be a smart learning environment, in which formal learning in classroom environments would be great transformed. It is important to notice that the eSchoolbag system can be installed on regular computers, Tablets or smart phones, making it pretty convenient for teachers and students without spatial and temporal limitations. Besides, the eSchoolbag is designed to be user-friendly. For example, the eSchoolbag can call the touch screen input, handwriting-recognition and other green applications if the device supports these features.

Numerous empirical findings pertaining to the effectiveness of the eSchoolbag in tailoring teaching and learning have documented its positive influences on students' learning performances. According to [3], the eSchoolbag does not only enhance students' interests in mathematics, but also change their learning approaches when integrated with the flipped classroom, resulting in a significant improvement in students' learning performances in consequence. The eSchoolbag is also helpful in developing learners' English oral communication abilities, as it provides students a wide range of authentic simulation environments and cognitive tools [9]. This is in line with the research of [10], which claimed that the eSchoolbag serves as an ecosystem of teaching and learning in the digital age, in which students' abilities of innovation, critical thinking, communication and leadership could be cultivated. However, few research exists on how students' prior learning performances affect their attitudes towards the eSchoolbag, specifically, students' technology acceptance, motivation and self-efficacy. It's quite possible that the higher performers show more motivation or self-efficacy than the low performers on using eSchoolbag to assist classroom-based learning.

\subsection{Technology Acceptance Model (TAM)}

Technology Acceptance Model (TAM) is a famous model proposed by Davis [11]. TAM provides a theoretical foundation to explain participants' technology adoption behaviors, and 
how users come to accept and use a technology or system. In TAM, perceived ease of use (PEOU) and perceived usefulness (PU) are two perceptions that reflect users' attitude towards technology. PEOU refers to what extend users believe that using a specific tool or system would be free from effort, while PU refers to degree to which users believe that using a specific tool or system would improve their performance [11]. TAM offers researchers and practitioners a method to study the process of applying new technologies in the classroom or workplace.

A majority of studies have used TAM to predict intention to use and actual use of e-learning system, social media, massive open online courses (MOOCs) [12]. Even though Davis's model has indicated the potential relationship between TAM factors and academic performance by defining that $\mathrm{PU}$ is an individual's belief of their performance, few studies in the literature have explored the direct relationship between TAM factors and academic performance. Some studies have examined the indirect effect of TAM factors on academic performance via mediators. For example, perceived ease of use and perceived usefulness were found positively associated with college students' learning environments satisfaction which is positively related to academic performance [13]. In other words, college students' perceived ease of use and perceived usefulness towards e-learning systems can indirectly predict academic performance. However, few studies have used TAM to examine the relationship among $\mathrm{K}-12$ students. As for K-12 students who may experience more influence from social comparison, their academic performance can have an effect on their perceived ease of use and perceived usefulness at the early stage of using a new technology. K-12 students who are identified as high or low performers based on their academic performance would be influenced by social comparison and evaluation. Parents and teachers exert pressure on students by comparing the students with others which will affect students' performance expectancy. Students who are identified as higher performers would have more self-confidence toward themselves. This kind of selfconfidence would bring higher performance expectancy. To be more specific, high performers are receiving more positive feedback from parents and teachers. The positive feedback will give students more confidence to achieve higher goal when learning with the eSchoolbag. Previous studies have already found that high performers with high performance expectancy have more belief towards the benefits of technology than low performers [14]. Therefore, high performers are supposed to think eSchoolbag more useful than low performers. Furthermore, high performers would think eSchoolbag more easy to use because they have higher self-competency. Based on these argument, the hypothesis is that high performers will consider eSchoolbag easier to use and more useful than low performers.

\subsection{Learning motivation}

Learning motivation can be defined as a form of cognitive and emotional arousal that stimulates, directs and maintains learning-related behaviors [15]. It's the result of interactions between learners' characteristics (e.g. prior knowledge and experience, cognitive development level, learning style) and their surrounding environmental factors. The intrinsic motivation and the extrinsic motivation are two essential constructs of learning motivation, which lie the foundation of a plenty of motivation theories, such as goal orientation models, expectancy-value theory, self-efficacy theory and self-determination theory. These theories provide researchers and instructors deep understanding of how learners' motivational components interplay with the learning environments and their learning performances. Though motivation theories vary, researchers have reached a consensus that instructors, parents and school administrators should create environments to foster students' motivation for the purpose of improving their learning outcomes. Without exception, in the eSchoolbag-based learning environment, students' motivation also plays a role in determining their final learning outcomes. For instance, empirical findings from our prior research have revealed that students with high motivation gained relatively higher learning achievements than those with low motivation [8].

It's important to notice that stimulus strategies of enhancing students' motivation cannot be effective without clarifying the inner states of their motivational components. For example, it would be inappropriate for instructors to keep emphasizing the importance of the eSchoolbag if their students just find it's hard to use. In a technology-rich environment, students' extrinsic learning motivation can be improved by fostering generative processing, such as adding appealing graphics or challenging scenarios according to students' characteristics and problem-solving contexts [16]. Students' intrinsic motivation can be enhanced by invoking their curiosity, control and recognition. Creating a challenge, competitive or cooperative learning atmosphere is also proved useful to booster students' intrinsic motivation [17] [18].

Since this study aims to reveal how students' prior learning performances affect their overall motivation, thus we didn't differentiate students' motivation components of using the eSchoolbag to assist classroom-based learning in this exploratory study. But it would be interesting to examine their motivational constructs into details if the influences exist. 


\subsection{Self-efficacy}

Bandura [19] proposed the concept of selfefficacy as one's belief in his or her ability to complete tasks or reach goals [19]. Self-efficacy beliefs control how people think, feel, motivate themselves and behave [20]. In general, people with high self-efficacy are more likely to make efforts to complete tasks, and to persist longer in those efforts, than those with low self-efficacy [21]. For example, students with high self-efficacy take difficult tasks as chances to be mastered rather than threats to be avoided. In order to succeed, students should have a robust sense of self-efficacy [20]. However, some research suggested that the ideal self-efficacy should be slightly above a person's ability, since people with high self-efficacy tend to set goals that are too high to complete [22].

Self-efficacy is measured as an individual's belief to execute an action or perform a task according to a specific situation [23]. In computer-based learning environments, self-efficacy is defined as students' self-confidence in their capabilities to use computers by seeking for information or help [24]. In terms of using eSchoolbag in this study, self-efficacy refers to students' belief in their ability to use eSchoolbag properly and independently for learning.

Self-efficacy has been used as an antecedent of academic performance in many studies. Within an academic context, the relationship between selfefficacy and academic performance had been explored across various subjects (including math, science, general success) in a range of learning environments (including early years, high school and university population) [25]. A meta-analysis of 12 years related studies found that self-efficacy moderately correlated with academic performance [25]. However, the causality between self-efficacy and performance remains to be established since no consistent results were found. Furthermore, fewer research has paid attention to the effect of academic performance on self-efficacy even though social comparison theory has already indicated a potential relationship. According to social comparison theory, students who are identified as high performers have more self-competency and performance expectancy than low performers [6]. In the context of learning with eSchoolbag, students whose previous academic performance are better than others would believe themselves more capable of learning with this new technology. Therefore, high performers are supposed to have higher self-efficacy than low performers in our study.

\section{Methods}

In order to examine the influences of students' prior academic performances on their technology acceptance, learning motivation and self-efficacy towards the eSchoolbag, an exploratory study was conducted.

\subsection{Participants}

A total of 299 participants from one middle school located in Shenzhen, China were involved in this study. In detail, all students were from the same grade (176 boys and 123 girls).

\subsection{Learning performance}

Students' learning performances were assessed through their scores in a serial of tests that elaborated designed by school teaching and research groups. Thus, the validity of these tests can be verified to some extent.

\subsection{Materials}

The questionnaire used in the study consists of five parts: demographic, learning motivation, selfefficacy, perceived ease-of-use, and perceived usefulness of the eSchoolbag.

Students' learning motivation was assessed by a questionnaire adapted from Pintrich and Groot [26]. In terms of self-efficacy, perceived ease-of-use, and perceived usefulness of the eSchoolbag, the questionnaires were derived from Hwang inTaiwan [27]. All items of the questionnaire were presented using a 5-point Likert scale with 1 stands for 'strongly disagree' and 5 as 'strongly agree'. To test the effect of the internal consistency of the questionnaire, reliability of the scale was analyzed. Specifically, the Cronbach's coefficient of the whole scale was 0.92. The Cronbach's coefficient of learning emotion, self-efficacy, perceived ease-ofuse, and perceived usefulness were $0.92,0.84,0.87$ and 0.90 respectively. 


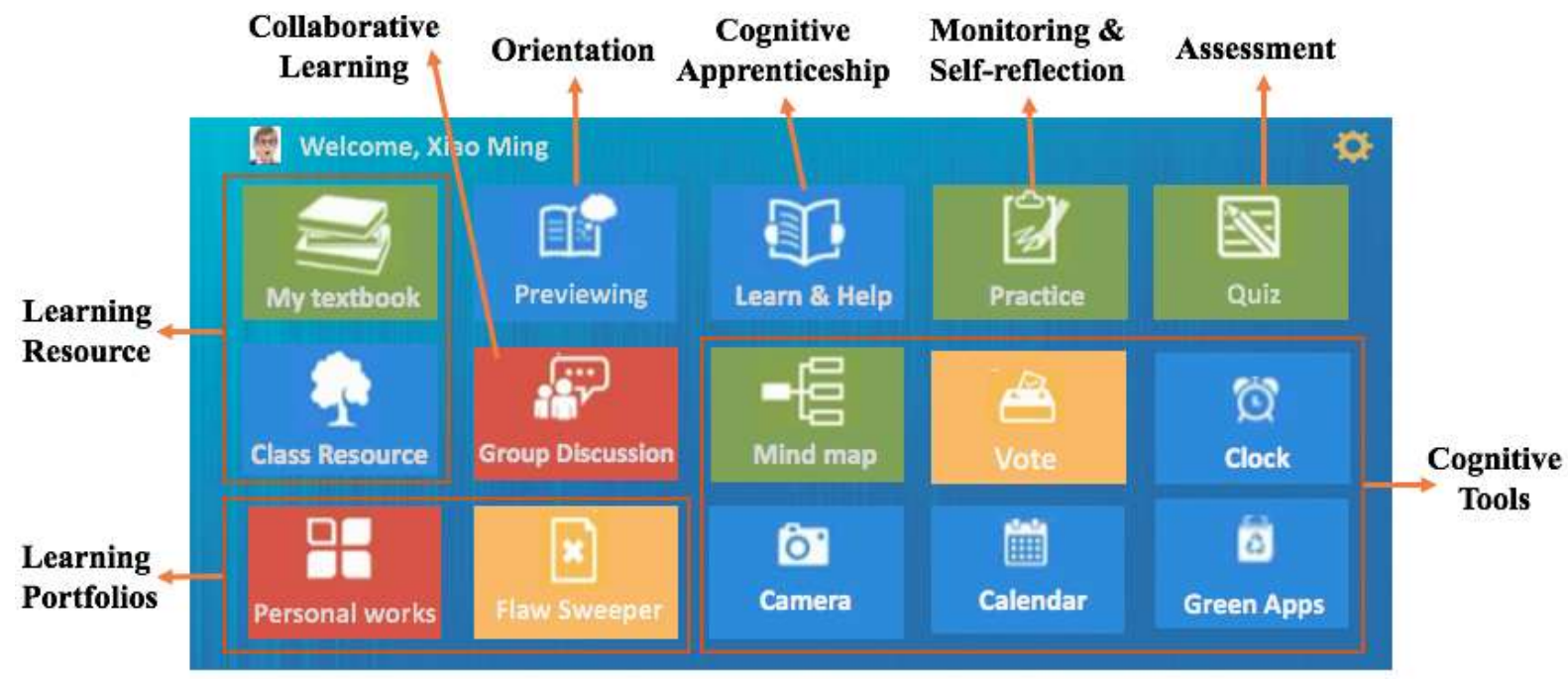

Figure 1. Description of features of the eSchoolbag software

Figure 1 provides an overview of the features of the eSchoolbag software. The eSchoolbag provides students technology-rich learning environment with kinds of learning resources, scaffoldings, cognitive and metacognitive tools. By using the eSchoolbag, students can learn and practice both in and out classrooms, without the limitation of time and place. When teachers release learning resource on the server side, students can have a view of the resource in My Textbook and Class Resource. Before the class, they can orientate and plan their learning by using the Previewing function on the eSchoolbag. In the Learn and Help part, the software provides students a cognitive-apprenticeship like environment to get immediate help from teachers. There is also an online Group Discussion where students can communicate with each other or work collaboratively to solve complex subject topics. In order to control their paces of learning, and adjust their learning based on their performance, students are provided with Practice and Quiz to monitor and assess their learning at the time they want. They can collect the mistakes or unfamiliar knowledge into Flaw Sweeper, thus they can have a review now and then. The eSchoolbag also includes several cognitive tools that promote cognitive monitoring and control strategies critical to classroom learning, such as mind map, vote, clock, calendar and camera.

\subsection{Procedures}

The study aims to reveal the effect of students' academic performance on eSchoolbag based learning. In order to conduct the research, the participants were divided into two groups according to their annual academic performance. Concretely, the two groups were created by using the K-means clustering algorithm, and named as the high and low group respectively. In detail, the centroid was 495 for the high group $(M=495, S D=42.2)$, and 350 for the low group $(M=350, S D=59.7)$ while the full score was 630 . They were relatively optimum cluster centroids in this study. Furthermore, there were 205 students in the high group, and 94 students in the low group (See Error! Reference source not found.).

Table 1. Grouping based on participants' academic performance

\begin{tabular}{lcccc}
\hline & Group & Number & $M$ & $S D$ \\
\hline Group 1 & High & 205 & 495 & 42.2 \\
Group 2 & Low & 94 & 350 & 59.7 \\
\hline
\end{tabular}

It's important to mention that students were unaware of the grouping, for the sake of minimizing exterior influences on students. Participants were given two-days of training which confirmed that all students had certain knowledge of the eSchoolbag. The same teacher conducted the training in the classroom environment. At the end of the training, all students were asked to finish a questionnaire.

\section{Results}

Analyses were performed with SPSS 21. An independent t-test was performed with the group (i.e. high group and low group) as the independent variable and students' perceived ease-of-use of the eSchoolbag as dependent variable. The results showed that there was no statistically significant difference between the two groups $(t$ (297) = $1.32, p=.188$, see Table 2). 
Table 2. Group difference on students' perceived ease-of-use of the eSchoolbag

\begin{tabular}{cccccc}
\hline Groups & $M$ & $S D$ & $t$ & $d f$ & Sig. \\
\hline High & 4.62 & .66 & 1.32 & 297 & .188 \\
Low & 4.52 & .61 & & & \\
\hline
\end{tabular}

An independent t-test was also performed with the group as the independent variable and students' perceived usefulness of the eSchoolbag as dependent variable. The result showed that there was statistically significant difference on students' perceived usefulness of the eSchoolbag between the high group and the low group $(t(297)=2.11, p=$ .037). See Table 3. Students in the high group had higher perceived usefulness towards the eSchoolbag $(M=4.60, S D=.63)$ than students in the low performance group $(M=4.41, S D=.73)$.

Table 3. Group difference on students' perceived usefulness of the eSchoolbag

\begin{tabular}{lccccc}
\hline Groups & $M$ & $S D$ & $t$ & $d f$ & Sig. \\
\hline High & 4.60 & .63 & 2.11 & 297 & $.037^{*}$ \\
Low & 4.41 & .73 & & & \\
\hline$* p<05$ & & & & &
\end{tabular}

In terms of students' motivation towards the eSchoolbag, there was no statistically significant difference between these two groups as determined by an independent t-test $(t(297)=1.11, p=.270$, see Table 4).

Table 4. Group difference on learning motivation

\begin{tabular}{lccccc}
\hline Groups & $M$ & $S D$ & $t$ & $d f$ & Sig. \\
\hline High & 4.20 & .95 & 1.11 & 297 & .270 \\
Low & 4.07 & .98 & & & \\
\hline
\end{tabular}

As for students' self-efficacy, the independent ttest showed that there was a statistically significant difference between the high group and the low group. $(t(297)=2.43, p=.016$, see Table 5). Students in the high group had higher self-efficacy $(M=4.54, S D=.63)$ than those in the low group $(M$ $=4.35, S D=.68)$.

Table 5. Group difference on self-efficacy

\begin{tabular}{cccccc}
\hline Groups & $M$ & $S D$ & $t$ & $d f$ & Sig. \\
\hline High & 4.54 & .63 & 2.43 & 297 & $.016^{*}$ \\
Low & 4.35 & .68 & & & \\
\hline
\end{tabular}

$* p<.05$

\section{Discussion}

With regard to students' perceived ease-of-use of the eSchoolbag, this research found that there was no significant difference between the high and low groups, indicating that students' prior learning performances had no significant influence on their perceptions of the ease-of-use of the eSchoolbag. As pointed out by [28], students nowadays are immersed in technology-rich environments both in and out school, making them adaptable to various digital technologies. Thus, when integrating the eSchoolbag into classrooms, students could accept and use it easily. This is in line with the popular viewpoint that the 'digital natives' who consider technology as their basic lifestyles have a tendency to master new technologies without much difficulties. However, there was a statistically significant difference on students' perceived usefulness of the eSchoolbag between these two groups, say, the high and the low learning performance group, suggesting that students do have different perceptions towards its usefulness in enhancing learning processes and outcomes. Students in the high group had more positive attitude towards the usefulness of the eSchoolbag than those in the low group. This can be explained by 1) students in the high group were better at linking the use of the eSchoolbag with their prior knowledge, which enables them to outline multiple possibilities of how to use the eSchoolbag in assisting their learning; 2) students in the high group had faster access to extract important information from the eSchoolbag, while those in the low group would take more time to identify the usefulness of the eSchoolbag. Thus, before using the eSchoolbag to assist teaching and learning in the classroom environment, it's better for instructors and administrators to clarify the deep reasons why students with low learning performances had relatively lower perceived usefulness of the eSchoolbag, and take actions to promote students' perceived usefulness of the eSchoolbag accordingly. In doing so, the successful implementation of the eSchoolbag can be guaranteed.

This research found that students had high motivation towards the eSchoolbag in general. Compared with the traditional lecture-based learning environment, students tend to have higher interests in using the eSchoolbag, a technology-rich and highlyinteractive learning environment, to assist their learning. First, the eSchoolbag provides students lots of cognitive and metacognitive scaffoldings which could help them effectively control, monitor and evaluate their learning processes; Second, the eSchoolbag grants students a personalized learning environment in which students can manage their learning materials, activities and artifacts; At last, the 
external factors, such as parents, school administrators and educational bureaus, had much expectations on the eSchoolbag, for the purpose of promoting educational reforms in primary and secondary schools [8]. Thus, the environmental factors could indirectly stimulate students to adopt and use the eSchoolbag. In addition, this research also found that there was no statistically significant difference on students' motivation between the high and low groups. This is in accordance with our prior research [8]. The reason partially lied in the fact the eSchoolbag is a new learning environment for all students. With the same opportunity of the exposure of the eSchoolbag, students in both groups were willing to have a try of the eSchoolbag.

It's well accepted that students' motivation is positively associated with their learning performances. Findings from this research suggested that students' prior learning performances had no significant influences on their motivation towards the eSchoolbag, which provides instructors important hints. First of all, teachers don't have to worry about their motivation towards the eSchoolbag at the beginning. However, effective intervention of students' motivation should be considered when it's necessary, considering that students' motivation varies and changes over time. Moreover, it's crucial for teachers to clarify what expectations do students have in different groups, though they have similar level of motivation. It's quite possible that students in the low group expected a significant improvement of their learning performances by leveraging the affordances of the eSchoolbag learning environment, while students in the high group hoped for an attracting and thought-provoking learning space. Thus, teachers should conciliate the motivation of both groups, which required more refined strategies.

In terms of students' self-efficacy towards the eSchoolbag, the result revealed that the high group was significant higher the low group, suggesting students in the high group had stronger beliefs of using eSchoolbag well than those in the low group. The underlying rationale is probably that students' success in learning performances had accumulated their self-efficacy in completing other tasks, such as using the eSchoolbag as a means of learning tool in classroom environment. According to [22], students' perceptions of self-efficacy are positively associated with their motivation, which means that the construct of motivation can be used to predict one's selfefficacy towards certain tasks, systems or environments. As aforementioned, students' motivation towards the eSchoolbag had no significant difference between the high and low groups, but it doesn't necessaries mean that their general motivation of performing well in various contexts are identical. In fact, this finding is in line with our expectations. Increasing successes build and consolidate a robust belief in one's personal efficacy, while failures undermine it [19]. In this research, students were divided into two groups based on their annual academic performances. It's a relatively long-term evaluation of their learning outcomes, thus it's reasonable to assume that students in the low group had no assurance in their capabilities to challenge a total different learning approach. As pointed out [20], one of the most effective way of strengthening the sense of efficacy is through the vicarious experiences provided by the person similar to oneself. That is, seeing students similar to oneself succeed in promoting learning performances by using the eSchoolbag could raise the observers' beliefs that they also possess the capabilities to succeed. Thus, to maximize the value of the eSchoolbag, teachers should pay attention to build a 'student model' who comes from the low group but improves a lot by using the eSchoolbag, which would stimulate the others in the low group to take the eSchoolbag as opportunities rather than threats.

\section{Conclusion}

The integration of information and technology into instructional practices has changed the classroom-based learning significantly. As a type of One-to-One learning environments, the eSchoolbag could meet both teachers' instructional requirements and students' learning needs. This research adds new evidences regarding the successful implementation of the eSchoolbag. Specifically, this study found that there were no significant differences on students' perceived ease-of-use and motivation towards the eSchoolbag between the high and low groups. However, significant differences were existed on students' perceived usefulness and self-efficacy between the two groups, with students in the high group demonstrating higher level of perceived usefulness and self-efficacy than those in the low group.

The findings in this paper will help decrease the mismatch between the implementation of eSchoolbag and students' realities, and further facilitate the successful adoption of the eSchoolbag in primary and middle schools. This is an exploratory study which provides several important implications for future research. To get a clearer understanding of students' technology acceptance, motivation and self-efficacy towards the eSchoolbag, on one hand, multiple approaches should be used to collect data, such as interviews, log files, and peer evaluation. On the other hand, a longitudinal analysis is needed to check how students' perceived ease-of-use, usefulness, motivation and self-efficacy change over time.

Besides, it's important to check students' motivation into details, though they showed high motivation in using the eSchoolbag and no 
significant difference was found between the high and low groups. For example, how students' motivational constructs, such as attainment value, intrinsic value and utility value towards the eSchoolbag develop during the use of the eSchoolbag. Specifically, Li \& Zheng [8] raised a motivational model of using eSchoolbag to learn English [8], in which attainment value is defined as students' perceived importance of using eSchoolbag to learn English courses. Intrinsic value refers to the students' enjoyment or interest of using eSchoolbag in English learning. Utility value is students' perceived usefulness of taking eSchoolbag as a mean to learn English, while cost refers to the extent of students' cognitive load during the use of the eSchoolbag. A closer examination of students' motivational constructs would provide teachers more information about students' inner ideas, thus making an effective intervention to promote students' motivation be possible.

In addition, future work will focus on how students' technology acceptance, motivation and self-efficacy account for their learning performances, and to what extent does each component justify students' learning outcomes.

\section{References}

[1] Ifenthaler, D., \& Schweinbenz, V. (2013). The acceptance of Tablet-PCs in classroom instruction: The teachers' perspectives. Computers in Human Behavior, 29(3), 525-534.

[2] Leinonen, T., Keune, A., Veermans, M., \& Toikkanen, T. (2016). Mobile apps for reflection in learning: A design research in K-12 education. British Journal of Educational Technology, 47(1), 184-202.

[3] Ni, M. etc. (2015). A study of an eSchoolbag supporting flipped classroom model for junior mathematics review class. In Lecture Notes in Computer Science (Vol. 9167, pp. 243-254).

[4] Mamat, K., \& Azmat, F. (2013). Mobile Learning Application for Basic Router and Switch Configuration on Android Platform. Procedia - Social and Behavioral Sciences, 90(0), 235-244.

[5] Dolenc, K., \& Aberšek, B. (2015). TECH8 intelligent and adaptive e-learning system: Integration into Technology and Science classrooms in lower secondary schools. Computers \& Education, 82(0), 354-365.

[6] Ghazvini, S. D. (2011). Relationships between academic self-concept and academic performance in high school students. In Procedia - Social and Behavioral Sciences (Vol. 15, pp. 1034-1039). https://doi.org/10.1016 /j.sbspro.2011.03.235
[7] Tajfel, H., \& Turner, J. C. (1986). The social identity theory of intergroup behavior. Psychology of Intergroup Relations. https://doi.org/10.1111/j.1751-9004.2007.00066 .x.

[8] Li, S., \& Zheng, J. (2017). The effect of academic motivation on students' English learning achievement in the eSchoolbag-based learning environment. Smart Learning Environments, 4(3). https://doi.org/10.1186/s405 61-017-0042-x.

[9] Xie, Y., Sun, N., Mei, X., Kong, Z., \& Kwok, L. F. (2016). Research of English Oral Communication Ability Cultivating Model in Junior Middle School Based on ESchoolbag. In Proceedings - 2015 International Conference of Educational Innovation Through Technology, EITT 2015 (pp. 247-252). https://doi.org/10.1109/EITT.2015.59.

[10] Wu, Y., Lin, L., Ma, X., \& Zhu, Z. (2013). Research on the E-textbook and E-schoolbag in China: constructing an ecosystem of E-textbook and E-schoolbag. Proceedings of the IADIS International Conference on Cognition \& Exploratory Learning in Digital Age, 225-232.

[11] Davis, F. D. (1989). Perceived usefulness, perceived ease of use, and user acceptance of information technology. MIS Quarterly, 13(3), 319-340.

[12] Wu, B., \& Chen, X. (2017). Continuance intention to use MOOCs: Integrating the technology acceptance model (TAM) and task technology fit (TTF) model. Computers in Human Behavior, 67, 221-232. https://doi.org/10.1016/j.ch b.2016.10.028.

[13] Lee, J. K., \& Lee, W. K. (2008). The relationship of eLearner's self-regulatory efficacy and perception of eLearning environmental quality. Computers in Human Behavior, 24(1), 32-47. https://doi.org/10.1016/j.chb.2006. 12.001 .

[14] Wang, Y. S., Wu, M. C., \& Wang, H. Y. (2009). Investigating the determinants and age and gender differences in the acceptance of mobile learning. British Journal of Educational Technology, 40(1), 92-118. https://doi.org/10.1111/j.1467-8535.2007.00809.x.

[15] Greeno, J., Collins, A. M., \& Resnick, L. B. (1997). Cognition and learning. In D. Berliner \& R. Calfee (Eds.), Handbook of educational psychology (pp. 15-46). New York: Simon \& Schuster McMillan.

[16] Mayer, R. E. (2014). Incorporating motivation into multimedia learning. Learning and Instruction, 171-173.

[17] Ciampa, K. (2014). Learning in a mobile age: An investigation of student motivation. Journal of Computer Assisted Learning, 30(1), 82-96. https://doi.org/10.1111/jc al.12036.

[18] Lajoie, S. P., \& Azevedo, R. (2005). Teaching and learning in technology-rich environments. In P. H. Winne (Ed.), Handbook of Educational Psychology (pp. 803821). Psychology Press. 
[19] Bandura, A. (1978). Self-efficacy: Toward a unifying theory of behavioral change. Advances in Behaviour Research and Therapy, 1(4), 139-161. https://doi.org/10.10 16/0146-6402(78)90002-4.

[20] Bandura, A. (1994). Self-efficacy. In V. S. Ramachaudran (Ed.), Encyclopedia of human behavior (Vol. 4, pp. 71-81). New York: Academic Press. (Reprinted in H. Friedman [Ed.], Encyclopedia of mental health. San Diego: Academic Press, 1998).

[21] Schunk, D. H. (1990). Goal Setting and Self-Efficacy During Self-Regulated Learning. Educational Psychologist, 25(1), 71-86.

[22] Schunk, D. (1991). Self-Efficacy and Academic Motivation. Educational Psychologist, 26(3), 207-231. https://doi.org/10.1207/s15326985ep2603\&4_2.

[23] Bandura, A. (1982). Self-efficacy mechanism in human agency. American Psychologist, 37(2), 122-147. https://doi.org/10.1037/0003-066X.37.2.122.

[24] Agudo-Peregrina, Á. F., Hernández-García, Á., \& Pascual-Miguel, F. J. (2014). Behavioral intention, use behavior and the acceptance of electronic learning systems: Differences between higher education and lifelong learning. Computers in Human Behavior, 34, 301314. https://doi.org/10.1016/j.chb.2013.10.035.

[25] Honicke, T., \& Broadbent, J. (2016). The influence of academic self-efficacy on academic performance: A systematic review. Educational Research Review, 17, 6384. https://doi.org/10.1016/j.edurev.2015.11.002.

[26] Pintrich, R. R., \& DeGroot, E. V. (1990). Motivational and self-regulated learning components of classroom academic performance, Journal of Educational Psychology, 82, 33-40.

[27] Chu, H., Hwang, G., Tsai, C., \& Tseng, J. C. R. (2010). A two-tier test approach to developing locationaware mobile learning systems for natural science courses. Computers \& Education, 55(4), 1618-1627.

[28] Gu, X., Zhu, Y., \& Guo, X. (2013). Meeting the "Digital Natives": Understanding the acceptance of technology in classrooms. Educational Technology and Society, 16(1), 392-402. 